American Journal of Psychiatric Research and Reviews
(ISSN:2637-479X)

\title{
Mental health and validity of the psycho-neurobiological stress model
}

\section{José M. BERTOLÍN-GUILLÉN}

Doctor and graduate in Medicine and Surgery; Specialist physician in Psychiatry; Graduate in Psychology; Head of Mental Health and Psychiatry Service (retired) in a Department of Health, Ministry for Universal Healthcare and Public Health, Government of Valencia, Spain, EU

\section{ABSTRACT}

Background and objectives: The public costs of self-reported mental stress and distress are enormous. And both the advance of neurobiology and the modern more biological approach of psychiatry as a whole are considerable. This work intends to provide an essential, updated and objective panoramic view on the neurobiology of all kinds of stress in relation to people's mental health and pathologies. Method: Bibliographic indexes such as Pubmed, Psycinfo Journal and Índices CSIC, were consulted, among others. The matter being tackled is extremely profuse, varied and complex, therefore the found literature has been as numerous as heterogeneous. It is also so dispersed that we have conducted a narrative non-systematic review that is intended to be impartial and balanced. Results: This article will concisely discuss the available, prominent and reliable scientific information regarding the main cerebral structures involved in the experience of stress, such as the hippocampus, prefrontal cortex, amygdala and hypothalamus. It will also comment on stress physiology, neuroendocrinology and associated psychopathology, as well as specifically certain genetic variations and linked molecular and immune activities. Conclusion: We have synthesised the relevant and current scientific knowledge of the correlations among stress, mental health and neurobiology as well as of their reciprocal interactions. There is increasing knowledge of these correlations and interactions, but it remains limited. Accordingly, further research is required.

Keywords: Anterior insular cortex; Basolateral amygdala; Functional genomics; Gene expression; Psychiatric genetics

\section{*Correspondence to Author:} José M. BERTOLÍN-GUILLÉN C/ Poeta Antonino Chocomeli, 5-4 46015 Valencia (España)

jmbertolin@comv.es

How to cite this article:

José M. BERTOLÍN-GUILLÉN. Mental health and validity of the psycho-neurobiological stress model. American Journal of Psychiatric Research and Reviews, 2022; 5:34.

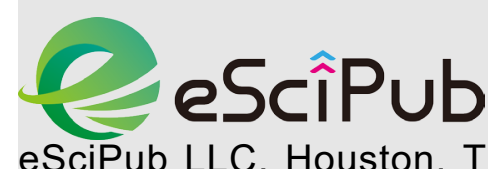
eSciPub LLC, Houston, TX USA. Website: https://escipub.com/ 


\section{INTRODUCTION}

The public costs of self-reported mental stress and distress are enormous. The terms "eustress" and "distress" are widely and frequently used in the international scientific literature. The major forerunners in the scientific study of stress were probably Robert Hooke in 1679, William James in 1884, and Walter Cannon in 1929, until the more recent, key figure of Hans Selye. Subsequent research is numerous and of varying quality.

Selye, considered the father of the current concept of "stress", categorised it as the nonspecific response of the organism to any demand. ${ }^{[1,2]}$ For him it is always a physiological -that is, biological- reaction. Stress of all kinds will leave a lasting impression on the body and influence future responses. When the reaction is inappropriate, harmful, global, excessive or long-lasting, it will clinically result in a "General Adjustment Syndrome" (GAS), although the response may also be only local.

Generally all living beings always experience varied and multiple stresses, whether of a physical, mental, environmental, or other nature, so healthy adaptation to them is fundamental. But it is when the physiological reaction reaches what Selye calls the "exhaustion phase" that the first symptoms appear. Bear in mind that what is excessive for one individual may not be so for another, as experiences and vulnerabilities, including particularly the biological ones, will differ.

This contribution aims succinctly and particularly to introduce the best scientific knowledge on the current state of the art regarding the more bodily or somatic aspects of the psycho-neurobiology of stress. The issue is extremely complex, varied and profuse. It will be set out below in a way that aims to be synthetic, organised and reasonably well structured.

\section{MATERIAL AND METHOD}

Note1 Corticosterone, a precursor of the mineralocorticoid aldosterone, is a glucocorticoid that is released together with cortisol. It is a steroid hormone from the
The following is a simplified narrative review of the most recent qualified literature in the fields of anatomophysiology of the nervous system and neurosciences in relation to stress from a varied and interdisciplinary perspective. This is becoming more and more important taking into account the novel neuromodulation and neurostimulation treatments for varied mental disorders, mainly for the depressive disorder. The relevant published information on the subject is enormous, disparate, and therefore unmanageable. So the aim here is merely to point out some notable, related scientific and biological advances.

With no claim to be exhaustive, but rather by highlighting the most innovative contributions, we have mainly reviewed, non-systematically, the indexes: PUBMED, SCILIT Indexing, PSYCINFO JOURNAL, and ÍnDICEs CSIC in Spanish, among others. The international research of the Psychiatric Genomics Consortium should be highlighted as probably representing some of the most remarkable, innovative and productive experiences in modern psychiatry. Its research has indeed made it possible to identify hundreds of common or rare genetic variations that contribute to the significant diversity that occurs in neuropsychiatric disorders.

\section{RESULTS AND DISCUSSION}

\section{Brain structures, neuroendocrinology and stress}

Stress-related psychosomatic responses are considered substantial health risk factors. There is evidence that the most notable bodily symptoms linked to stress are associated with a smaller volume in the prefrontal, insula and limbic system brain regions, which are involved in processing emotion, interoception and memory. ${ }^{[3]}$ Noradrenergic transmission in the basolateral amygdala and changes in the concentration of corticosterone $\mathrm{Note1}^{\text {in }}$ this brain

adrenalcortex, which regulates the metabolism of lipids, carbohydrates and proteins. 
area are critical in the acquisition and consolidation of emotional memory. ${ }^{[4]}$

The neural mechanisms underlying the affective-emotional and neuroendocrine experience of stress are becoming increasingly clear. [5] In short, stress involves the hippocampus, the prefrontal cortex, the amygdala, the hypothalamus, ${ }^{\text {Note2 }}$ as well as the hypophysis ${ }^{\text {Note } 3}$ and the adrenal cortex glands with their secretion of glucocorticoids and androgens. As is well known, pituitary functions are regulated by the hypothalamus. Scientific evidence indicates that amygdala activity enables functional interactions between the prelimbic and anterior insular cortex and the dorsal hippocampus in the regulation of stress hormones and in the memory effects of emotional arousal. ${ }^{[6]}$ The main stress hormone is cortisol or hydrocortisone, which is produced in the fascicular layer of the adrenal cortex.

The key Framingham Heart Study (Massachusetts, USA, 2018) confirmed that significantly increased serum cortisol was associated with lower brain volumes and memory impairment in asymptomatic young to middle-aged adults, and this association was particularly evident in women. ${ }^{[7]}$ In particular, increased cortisol levels in hair have been significantly associated with reduced lobar and global brain volumes in frontal, temporal and cingulate regions. ${ }^{[8]}$

Neurons in the paraventricular nucleus of the hypothalamus that produce corticotropinreleasing hormone $(\mathrm{CRH})$ are rapidly activated in response to stress, and cortisol mediates energy mobilisation during stress. Rapid increases in glucocorticoid hormones (or steroids, i.e. compounds chemically derived from cholesterol) allow an adaptive response to immediate challenges, but can also have the

Nota2 The hypothalamus secretes the adrenocorticotropic hormone, also called corticoliberin, corticotropin-releasing hormone $(\mathrm{CRH})$, or corticotropin-releasing factor (CRF).

Note3 The pituitary gland secretes the adrenocorticotropic hormone (ACTH) also called corticoliberin, corticotrophinreleasing hormone $(\mathrm{CRH})$, or corticotrophin-releasing factor (CRF). negative consequence of inducing cellular oxidative stress. [9] This is the mechanism underlying the development of endothelial dysfunction. As is well known, the initial effect of any stress is mediated by the sympathetic (noradrenergic) branch of the autonomic nervous system and is followed by activation of the hypothalamic-pituitary-adrenal (HPA) axis.

The HPA axis is an important primary neuroendocrine mediator of neural and behavioural responses to stress. When activation of this axis is prolonged or chronic, among other consequences, it will negatively influence adult neurogenesis, especially in the medial prefrontal region, which will limit the individual's coping capacity. It has been hypothesised that chronic dysregulation of the HPA axis will cause changes in stress-related brain circuits, which may influence the subject's behavioural response to stressful exposure. ${ }^{[10]}$

LociNote4 have been found to be associated with at least two mental disorders, including quite a few of these loci with pleiotropic effects ${ }^{\text {Note }} 5$ in four or more disorders. There is also a smaller number of loci associated with antagonistic effects in multiple disorders. ${ }^{[11]}$ Major depressive disorder and neuroticism share a strong genetic basis, although there are characteristics of depression that are not related to neuroticism. ${ }^{[12]}$ Recent findings have shown that the coexpressive combination of the proteins of genes CEP350, SMAD5 and HSPG2 have a relatively high diagnostic and pathogenic value for major depression ${ }^{[13]}$.

On the other hand, addiction and depression have overlapping neural circuits and similar molecular mechanisms ${ }^{[14]}$. In particular, the variation in the underlying gene architecture explains a substantial proportion of the numerous and often complex clinical diagnoses

Note4 In the text, the Latin term "loci" (plural form of "locus") refers to the fixed position occupied by any gene on a chromosome.

Note5 Recall that "pleiotropy" refers to the phenotypic effects or distinct and unrelated traits that are linked to a single gene or allele. 
of anxiety. More specifically, the anxiety symptom has shown significant positive genetic correlations, among other disorders, with depressive disorders, as well as with the insomnia symptom. ${ }^{[15]}$

In relation to memory and affective-emotional experiences, the ventromedial prefrontal cortex is known to drive hippocampal activity during memory processing. It also plays a key role in shaping the affective-emotional responses that arise from autobiographical memories. ${ }^{[16]}$ On the other hand, adrenal catecholamines ${ }^{\text {Note } 6}$ can also be secreted at nerve endings as neurotransmitters. ${ }^{\text {Note7 }}$ It is when adrenaline and noradrenaline bind to adrenergic receptors widely distributed in the rest of the body that they cause the immediate, subjective experience of stress, and retroactively inform the hypothalamus.

Chronic activation and dysregulation of the neuroendocrine response to stress have both physiological and specifically mental consequences. In particular, stressors of a more psychic nature or effect are stimuli that threaten the individual's current or proximate equilibrium, or that provoke a state of anticipation even if they do not represent an immediate realistic threat. They must be processed by the cerebral cortex before initiating the adaptive psychophysical response and will be influenced to a large extent, where applicable, by previous experiences.

On the other hand, in men and women, different neural networks appear to be involved during stress, although no gender-specific cognitive biases have been found between sex and stress. $[7,17]$ There do appear to be significant gender differences in terms of prevalence, symptom

${ }^{\text {Note6 }}$ Adrenal catecholamines are hormones that do not act directly on the brain as they do not cross the blood-brain barrier.

Note7 Although it goes without saying, the main catecholamines are dopamine (which acts primarily as a neurotransmitter in the central nervous system) and its derivatives adrenaline (or epinephrine, synthesised in the adrenal medulla) and noradrenaline (or norepinephrine, furthermore synthesised in the peripheral sympathetic nerves). The adrenal cortex is trophically regulated, among other factors, by the pituitary gland via profiles, severity and comorbidities of mental disorders. According to some authors, women have been shown to be more vulnerable to stress and are almost twice as likely as men to develop certain related disorders, such as depressive and anxiety disorders. ${ }^{[18]}$

\section{Physiological and psychopathological aspects of stress}

The organic processes of the biological concept of adaptive allostasis to stress load are fragile and can quickly be decompensated. As a result, molecular and physiological rebalancing, or homeostasis, may be uncertain. This rebalancing will be of utmost importance for psychiatry and clinical psychology when persistent behavioural, mood, ideational or cognitive changes occur. There is growing evidence that stress-induced brain cytokines are important in the aetiology of depression and anxiety. Catecholamines and glucocorticoids play a key role in cytokine regulation following exposure to psychological stress. ${ }^{[19]}$

We have an incomplete understanding of the molecular pathology involved in mental disorders and the need for a promising and innovative personalised or "precision psychiatry" has been repeatedly highlighted. "Clinical metabolomics", Note 8 the latest in the "omics" sciences, ${ }^{\text {Note }} 9$ has even been proposed as a promising tool for psychopathological diagnosis. [20.21] To this should be added the equally promising importance of oxidative research for psychiatry. [22] Nuclear magnetic resonance spectroscopy and mass spectrometry are the two key platforms for measuring the changing metabolome, ${ }^{\text {Note } 10}$ so closely linked to precision medicine.

adrenocorticotrophin or adrenocorticotropic hormone (ACTH), mentioned above in Note 3.

${ }^{\text {Notes }}$ Metabolomics studies the repertoire of biochemical products (or small molecules) present in cells, tissues and body fluids.

Note9 "Omics" are the sciences that make it possible to investigate a large number of molecules involved in the organism's biological functioning processes.

Note10 The "metabolome" includes secondary metabolic intermediates and hormones. It can be used to determine the risk of developing a disease or disorder in the long AJPRR:https://escipub.com/american-journal-of-psychiatric-research-and-reviews/ 
Recently, it has been suggested that the study of personality improves blood metabolome analysis and biotyping of major depressive disorders. ${ }^{[23,24]}$ For frequent depression and anxiety comorbidity, it has been suggested that altered inflammatory metabolomic profiles related to atherogenic lipoproteins ${ }^{\text {Note } 11}$ are more associated with clinical depression than with anxiety disorders. [25] With respect to multifactorial anxiety disorders, it is believed that both psychological and biological factors are involved in their aetiology, specifically genetic and chemical factors among the latter. [26]

In short, Selye's concepts of stress and EMS are still valid today, although there are a number of nuances. These concepts, which are generally different for sociology and psychology compared to biomedicine, have been expanded and evolved significantly. The response to the stressful situation will commonly have a nonspecific neurophysiological aspect, well described by Selye, and a specific one that will depend more on the subject, including their genetics and biology in general, their knowledge of the stressful situation or event, resilience and choice of reactions, whether adaptive or nonadaptive.

Stress maladaptation happens, for example, with the perhaps over-emphasised "posttraumatic stress disorder" (PTSD) and could also happen with what will be referred to in ICD-11 as "complex" PTSD. [27] Furthermore, the ICD-11 and the 2013 Diagnostic and Statistical Manual of Mental Disorders have different proposals in this respect. Therefore, the stressor will be causal and necessary to condition the physiological reaction, but not sufficient to cause or determine psychopathological symptoms.

As a reinforcing link between psychosocial stress and its neurobiological effects, there is growing scientific evidence to suggest that

term. The person's metabolic status provides a valid, close representation of his or her overall health status.

Note11 Four main groups of lipoproteins have been identified, based on their density: chylomicrons, very lowdensity lipoproteins (VLDL), low-density lipoproteins (LDL) and high-density lipoproteins (HDL). Triglyceride-rich epigenetic changes ${ }^{\text {Note } 12}$ are a key mechanism by which persistent stressors interact with the genome and lead to stable changes in deoxyribonucleic acid structure, gene expression and behaviour. And it is very clear that genome variation in human populations is the basis of evolution.

On the other hand, in rats, hypofunction of $\mathrm{N}$ Methyl-D-Aspartate (NMDA) receptors in the prelimbic region of the prefrontal cortex can alter long-term memory processing of aversive stimuli. Such an alteration would occur without changing the short-term parameters of stress response, such as increases in noradrenaline and corticosterone in the amygdala. [28]

In short, repeated or prolonged stressors experienced by the subject, including those linked to poor social relationships, will usually lead to structural changes in the prefrontal cortex, the hippocampus and the basolateral amygdala, among other biological consequences. ${ }^{[29]}$ In contrast, perceived social support and the quality of interpersonal relationships, as well as their longer duration, have been related to lower experiences of stress. [30] Naturally, a reasonably optimal degree of stress is essential to build adequate biological "shields".

It has been recently proposed that the combination of temperamental traits (neuropsychological factor), child adversity (social) and transmission of an inadequate adjustment of dopamine may increase the risk of several mental disorders of early onset, commonly comorbid, and predicts this susceptibility in a prospective way. ${ }^{[31]}$ In such way, there exists first evidence that the early onset disorders may reflect to a large extent differentiated expressions of a small number of

lipoproteins and their remnants or leftovers are atherogenic.

Note12 Epigenetics refers to reversible changes in DNA that cause genes to be expressed or not, depending on external conditions. Epigenetic information modulates

gene expression without altering the DNA sequence. 
biological, neuropsychological and social factors.

There are already studies that reliably identify neurobiological changes in depressive disorders. ${ }^{\left[{ }^{22]}\right.}$ Stress is arguably a significant risk factor for the development of major depressive disorder. There is a clear increase in the prevalence of depression with the onset of puberty, and it has been suggested that the effects of testosterone on mood in adolescent boys with clinical depression depend, in part, on the genetic make-up of the androgen receptor (hAR), which is located on the long arm of the $X$ chromosome (qX 11-12). ${ }^{[33]}$ In a sample of patients with this disorder, glutamatergic adaptation to stress was also characteristically impaired. [34]

Stress: genetics, gestation, molecular and immune activities

Continuing with an interdisciplinary approach, several alterations of the immune system have been associated with the presence of mental disorders. These include predominantly proinflammatory dysregulation of the organ stress response, [35] as discussed in the previous subsection on altered inflammatory metabolomic profiles. The gut-brain-microbiota axis, in particular, could be a promising therapeutic target for stress-induced behavioural disturbances, as it simultaneously modulates peripheral and brain immune processes. ${ }^{\left[{ }^{[6,37]} \text { It }\right.}$ has been emphasised that modulators of the complex ecosystem of the gut microbiota associated with antidepressant and antipsychotic drugs may be an effective adjuvant therapy for certain mental disorders. [38]

Estimates of heritability data, i.e. the proportion of biological trait variants between siblings, range from 0.30 for major depression to an impressive 0.80 for Attention Deficit Disorder and Hyperactivity (ADDH). ${ }^{[39]}$ Consequently, it will be critical to closely monitor and follow the

Note13 Eicosanoids are derivatives of polyunsaturated fatty acids with 20 carbon atoms. mental health of the first-degree relatives of any subjects diagnosed with ADDH. ${ }^{[40]}$

It has recently been suggested that modulation of ABCB1 gene function may be important in the development of therapeutic strategies for patients suffering from stress-related metabolic mental disorders. ${ }^{[41]}$ It has also been proposed that depressive behaviours induced by the subjective feeling of stress due to repeated and continuous social defeats are significantly associated with the reduction of histone deacetylase HDAC7 in the nucleus accumbens. [42]

Inflammatory pathways appear to predict nonresponse to antidepressant treatment in major depression. Exposure to chronic stress will lead to impairment of the hypothalamic-pituitaryadrenal system, leading the body into proinflammatory states mediated by interleukins and glucocorticoids. The lipid compounds "eicosanoids", ${ }^{\text {Note }}{ }^{13}$ a family of metabolites derived from oxygenated polyunsaturated fatty acids, play a crucial role in inflammatory mechanisms and have been implicated in disorders such as anorexia nervosa and clinical depression.

In general, resilient individuals have a different immunophenotype to those who are more susceptible to stress. It is possible to make susceptible individuals resistant and vice versa by changing their inflammatory phenotype. We should add the caveat that genetics does not necessarily determine behaviour as a phenotype, although it does condition it. Thus, we refer rather to a probabilistic connection between genetic factors and behavioural differences between individuals, where genephenotype relationships will be crucial for marking these differences. This nuance is important in what is usually called "behavioural genetics".

With respect to stress in general, considerable and appropriate progress has been made in 
detecting, quantifying and applying certain genetic biomarkers of stress. ${ }^{[43]}$ The proteincoding genes FKBP5, DDX6, B2M, LAIR1, RTN4 and NUB1 are the biomarkers with the best converging global functional evidence for involvement in stress. ${ }^{[44]} \mathrm{New}$ or newly indicated drug candidates for the pharmacogenomic treatment of mood disorders have recently been bioinformatically identified. ${ }^{[45]}$

Modulation of the bi-directional relationships between resilience and immunity by the gut microbiota opens up the possibility of influencing both through probiotic foods or additional charges (containing living organisms) and specialised plant fibres that are prebiotics. ${ }^{[46]}$ On the other hand, "ghrelin" has recently been identified as a new stress biomarker: it is a hormone that promotes regulation of the energy metabolism, increasing in the short term after acute stress. ${ }^{[47]}$

Maternal exposure to severe stress may disrupt maternal adaptive brain changes and influence, more particularly, their neural circuits of stress regulation and motivation. This may well explain the altered responses of stressed mothers to timely infant signals. ${ }^{[48]}$ We know that chronic stress interferes with immune homeostasis. New immune mechanisms have been proposed to underlie the impact of adversity on health during the particularly sensitive stages of embryonic and early childhood. [49]

Pregnancy and early childhood are indeed the two periods of greatest immunological plasticity. Maternal stress in the prenatal period of pregnancy induces hippocampal alterations in the foetus. And an individual's early life stress, including any form of adversity, represents a biological fingerprint that will increase the lifetime risk of mood, anxiety and substance use disorders. Indeed, early life stress may alter the development, function and motivated behaviours of the brain's reward circuitry. ${ }^{[50,51]}$

In this circuit, terminating in the frontal lobes, the nucleus accumbens and ventral tegmental area are particularly important. As is well known, the reward circuit is closely linked to basic needs.
Meanwhile, alterations have likewise been proposed in the molecular mechanisms of development and intergenerational trajectories of survivors of repeated violent experiences. ${ }^{52]}$

Processes such as neurogenesis and synaptic plasticity are clearly affected by a variety of factors, including stress. On the other hand, stress-induced cortical alertness will subsequently be maintained by the increased persistent excitability of noradrenergic neurons that innervate, in particular, the prefrontal cortex. Excessive prenatal maternal distress is likely to contribute unique shared effects to the formation and development of both the brain and behaviour of the newborn. ${ }^{[53]}$

Finally, brain-derived neurotrophic factor (BDNF), a protein that is a critical member of the neurotrophic family, plays an important role in multiple stress-related mental disorders (e.g. depressive disorder), promoting the growth and proliferation of cells in the hippocampus. BDNF is one of the most studied neurotrophins, and is predicted to be important in treating mental and neurodegenerative disorders. [54,55] Antidepressant drugs have upregulating effects on BDNF concentrations, whereas BDNF concentrations are decreased in sustained stress and depression.

\section{CONCLUSIONS}

The amygdala's activity enables functional interactions between the anterior prelimbic and insular cortex and the dorsal hippocampus in regulating stress hormones, the main one being cortisol. High serum concentrations are associated with reduced volumes in frontal, temporal and cingulate brain regions.

When stress is prolonged, the HPA axis will negatively influence adult neurogenesis, especially in the medial prefrontal region, limiting the individual's coping capacity. Chronic stress will affect the HPA axis, leading to proinflammatory states mediated by interleukins and glucocorticoids.

In the psychopathological domain, depressive and anxiety disorders share some genetic 
bases. There appear to be important differences between men's and women's experience of stress in terms of severity and prevalence of related mental disorders. From a therapeutic perspective, modulation of the $A B C 1$ gene specifically for stress-related metabolic disorders could be relevant. Certain protein modifier genes have been shown to be good biomarkers of stress, as has the hormone ghrelin.

Gestation and early childhood are the periods of greatest biological vulnerability to stress, including the foetal repercussions of maternal stress. Neurogenesis and synaptic plasticity will be particularly affected in this early life stage. And it has been predicted that the neurotrophin BDNF will be important in treating subsequent mental and neurodegenerative pathologies.

Advances in modern neurobiology undoubtedly allow new interdisciplinary approaches to the anatomo-physiological concept of stress in relation, above all, to certain mental disorders. This is what we have sought to emphasise in an up-to-date, concise manner in this panoramic review study.

As a final observation, there are undoubted reciprocal relationships between the stress experienced -including psychosocial stressand the subject's neuroendocrine and immune systems. Knowledge of their interactions is growing but still very limited. Thus, more research is still needed to further investigate the neurobiology of stress.

\section{CONFLICTS OF INTEREST: None}

FINANCING: This research has not received any specific aid from public sector agencies, the commercial sector or non-profit organisations.

ETHICAL CONSIDERATIONS: All the pertinent ethical norms have been respected.

\section{References}

[1]. Selye H. Homeostasis and heterostasis. Perspect Biol Med. 1973;16(3):441-5. https://doi.org/10.1353/pbm. 1973.0056

[2]. Selye H. History and present of the status of the stress concept. In: Golberger L, Breznitz S., editors. Handbook of stress. Theoretical and clinical aspects. 2nd ed, New York: Free Press; 1993, pp. 7-17.

[3]. Wei D, Liu Y, Zhuang K, Lv J, Meng J, Sun J, et al. Brain structures associated with individual differences in somatic symptoms and emotional distress in a healthy sample. Front Hum Neurosci. 2020;14:492990. https://doi.org/10.3389/fnhum.2020.492990

[4]. Chen Y, Barsegyan A, Nadif-Kasri N, Roozendaal B. Basolateral amygdala noradrenergic activity is required for enhancement of object recognition memory by histone deacetylase inhibition in the anterior insular cortex. Neuropharmacology. 2018;141:32-41.

https://doi.org/10.1016/j.neuropharm.2018.08. 018

[5]. Duval F, González F, Rabia H. Neurobiología del estrés. [Neurobiology of stress.] Rev Chil Neuro-Psiquiatr. $\quad$ 2010;48(4):307-18. https://www.scielo.cl/pdf/rchnp/v48n4/art06.pd $f$

[6]. Barsegyan A, Mirone G, Ronzoni G, Guo C, Song $Q$, van Kuppeveld $D$, et al. Glucocorticoid enhancement of recognition memory via basolateral amygdala-driven facilitation of prelimbic cortex interactions. Proc Natl Acad Sci USA. 2019;116(14):7077-82.

https://doi.org/10.1073/pnas.1901513116

[7]. Echouffo-Tcheugui JB, Conner SC, Himali JJ, Maillard P, DeCarli CS, Beiser AS, et al. Circulating cortisol and cognitive and structural brain measures: The Framingham Heart Study. Neurology. 2018;91(21):e1961-e1970. https://doi.org/10.1212/WNL.0000000000006 549

[8]. Green C, Stolicyn A, Harris MA, Shen X, Romaniuk L, Barbu MC, et al. Hair glucocorticoids are associated with childhood adversity, depressive symptoms and reduced global and lobar grey matter in Generation Scotland. Transl Psychiatry. 2021;11(1):523. https://doi.org/10.1038/s41398-021-01644-9

[9]. Majer AD, Fasanello VJ, Tindle K, Frenz BJ, Ziur $A D$, Fischer $C P$, et al. Is there an oxidative cost of acute stress? Characterization, implication of glucocorticoids and modulation by prior stress experience. Proc Biol Sci. 2019;286(1915):20191698.

https://doi.org/10.1098/rspb.2019.1698

[10]. Kinlein SA, Phillips DJ, Keller CR, Karatsoreos IN. Role of corticosterone in altered neurobehavioral responses to acute stress in a model of compromised hypothalamicpituitary-adrenal axis function. 
Psychoneuroendocrinology.

2019;102:248-55.

https://doi.org/10.1016/j.psyneuen.2018.12.01 0

[11]. Cross-Disorder Group of the Psychiatric Genomics Consortium. Genomic relationships, novel loci, and pleiotropic mechanisms across eight psychiatric disorders. Cell. 2019;179(7):1469-82.e11. https://doi.org/10.1016/j.cell.2019.11.020

[12]. Adams MJ, Howard DM, Luciano M, Clarke TK, Davies G, Hill WD; et al. Genetic stratification of depression by neuroticism: Revisiting a diagnostic tradition. Psychol Med. 2020;50(15):2526-35.

https://doi.org/10.1017/S0033291719002629

[13]. Long $Q$, Wang R, Feng M, Zhao X, Liu Y, Ma $X$, et al. Construction and analysis of a diagnostic model based on differential expression genes in patients with major depressive disorder. Front Psychiatry. 2021. https://doi.org/10.3389/fpsyt.2021.762683

[14]. Xu L, Nan J, Lan Y. The nucleus accumbens: A common target in the comorbidity of depression and addiction. Front Neural Circuits. 2020;14:37. https://doi.org/10.3389/fncir.2020.00037

[15]. Purves KL, Coleman JRI, Meier SM, Rayner C, Davis KAS, Cheesman R, et al. A major role for common genetic variation in anxiety disorders. Mol Psychiatry. 2020;25(12):3292-303.

https://doi.org/10.1038/s41380-019-0559-1

[16]. Nawa NE, Ando H. Effective connectivity within the ventromedial prefrontal cortexhippocampus-amygdala network during the elaboration of emotional autobiographical memories. Neuroimage. 2019;189:316-28. https://doi.org/10.1016/j.neuroimage.2019.01. 042

[17]. Dumont L, Marin MF, Lupien SJ, Juster RP. Sex differences in work-stress memory bias and stress hormones. Brain Sci. 2020;10(7):432.

https://doi.org/10.3390/brainsci10070432

[18]. Takahashi A. Toward understanding the sex differences in the biological mechanism of social stress in mouse models. Front Psychiatry. $\quad 2021 ; 12: 644161$. https://doi.org/10.3389/fpsyt.2021.644161

[19]. Johnson JD, Barnard DF, Kulp AC, Mehta DM. Neuroendocrine regulation of brain cytokines after psychological stress. J Endocr Soc. 2019;3(7):1302-20.

https://doi.org/10.1210/js.2019-00053
[20]. Shih PB. Metabolomics biomarkers for precision psychiatry. Adv Exp Med Biol. 2019;1161:101-13.

https://doi.org/10.1007/978-3-030-217358_10

[21]. Letertre MPM, Giraudeau P, de Tullio P. Nuclear magnetic resonance spectroscopy in clinical metabolomics and personalized medicine: Current challenges and perspectives. Front Mol Biosci. $2021 ; 8: 698337$.

https://doi.org/10.3389/fmolb.2021.698337

[22]. Erjavec NG, Konjevod M, Perkovic MN, Strac DS, Tudor L, Barbas C, et al. Short overview on metabolomic approach and redox changes in psychiatric disorders. Redox Biol. 2018;14:178-86.

https://doi.org/10.1016/j.redox.2017.09.002

[23]. Beger RD, Dunn W, Schmidt MA, Gross SS, Kirwan JA, Cascante M, et al. Metabolomics enables precision medicine: "A White Paper, Community Perspective". Metabolomics. 2016;12(9):149.

https://doi.org/110.1007/s11306-016-1094-6

[24]. Setoyama D, Yoshino A, Takamura M, Okada G, Iwata M, Tsunetomi K, et al. Personality classification enhances blood metabolome analysis and biotyping for major depressive disorders: Two-species investigation. J Affect Disord. 2021;279:20-30. https://doi.org/10.1016/j.jad.2020.09.118

[25]. de Kluiver H, Jansen R, Milaneschi $Y$, Bot M, Giltay EJ, Schoevers R, et al. Metabolomic profiles discriminating anxiety from depression. Acta Psychiatr Scand. 2021;144(2):178-93. https://doi.org/10.1111/acps. 13310

[26]. Humer E, Pieh C, Probst T. Metabolomic biomarkers in anxiety disorders. Int J Mol Sci. 2020;21(13):4784.

https://doi.org/10.3390/ijms21134784

[27]. Redican E, Nolan E, Hyland P, Cloitre M, McBride $O$, Karatzias $T$, et al. A systematic literature review of factor analytic and mixture models of ICD-11 PTSD and CPTSD using the International Trauma Questionnaire. J Anxiety Disord. 2021;79:102381. https://doi.org/10.1016/j.janxdis.2021.102381

[28]. Ronzoni-Blázquez G. Corteza prefrontal, amígdala y estrés: estudio de la noradrenalina, corticosterona y memoria aversiva en la rata. [Prefrontal cortex, amygdala and stress: Study of norepinephrine, corticosterone and aversive memory in the rat.] Doctoral thesis. Madrid, ES: Faculty of Medicine, Complutense University; 2015. 
[29]. Munshi S, Loh MK, Ferrara N, DeJoseph MR, Ritger A, Padival M, et al. Repeated stress induces a pro-inflammatory state, increases amygdala neuronal and microglial activation, and causes anxiety in adult male rats. Brain Behav Immun. 2020;84:180-99. https://doi.org/10.1016/j.bbi.2019.11.023

[30]. Stoffel M, Abbruzzese E, Rahn S, Bossmann $\mathrm{U}$, Moessner M, Ditzen B. Covariation of psychobiological stress regulation with valence and quantity of social interactions in everyday life: Disentangling intra- and interindividual sources of variation. J Neural Transm (Vienna). 2021;128(9):1381-95. https://doi.org/10.1007/s00702-021-02359-3

[31]. Iqbal M, Cox SML, Jaworska N, Tippler M, Castellanos-Ryan N, Parent S, et al. A threefactor model of common early onset psychiatric disorders: Temperament, adversity, and dopamine. Neuropsychopharmacology. 2021. https://doi.org/10.1038/s41386-021-01187-z

[32]. Park C, Rosenblat JD, Brietzke E, Pan Z, Lee $Y$, Cao B, et al. Stress, epigenetics and depression: A systematic review. Neurosci Biobehav Rev. 2019;102:139-52. https://doi.org/10.1016/j.neubiorev.2019.04.01 0

[33]. Hirtz R, Libuda L, Hinney A, Focker M, Buhlmeier J, Martin P, et al. Size matters: The CAG repeat length of the androgen receptor gene, testosterone, and male adolescent depression severity. Front Psychiatry. 2021. https://doi.org/10.3389/fpsyt.2021.732759

[34]. Cooper JA, Nuutinen MR, Lawlor VM, DeVries BAM, Barrick EM, Hossein S, et al. Reduced adaptation of glutamatergic stress response is associated with pessimistic expectations in depression. Nat Commun. 2021;12(1):3166. https://doi.org/10.1038/s41467-021-23284-9

[35]. Soria V, Uribe J, Salvat-Pujol N, Palao D, Menchón JM, Labad J. Psychoneuroimmunology of mental disorders. Rev Psiquiatr Salud Ment (Barc). 2018;11:115-24. https://doi.org/10.1016/j.rpsm.2017.07.006

[36]. Ochoa-Repáraz J, Ramelow CC, Kasper LH. A gut feeling: The importance of the intestinal microbiota in psychiatric disorders. Front Immunol. 2020;11:510113. https://doi.org/10.3389/fimmu.2020.510113

[37]. Westfall S, Caracci F, Estill M, Frolinger T, Shen L, Pasinetti GM. Chronic stress-induced depression and anxiety priming modulated by gut-brain-axis immunity. Front Immunol.
$2021 ; 12: 670500$

https://doi.org/10.3389/fimmu.2021.670500

[38]. Jimenez-Badilla I, Acuña-Amador L. Evidencias clínicas del uso de moduladores de la microbiota intestinal para el tratamiento de trastornos mentales: una revisión bibliográfica sistemática. [Clinical evidence about the use of gut microbiota modulators as treatment for mental health disorders: A systematic review.] Psiquiatr Biol. 2021;28(2):100315. https://doi.org/10.1016/j.psiq.2021.100315

[39]. Pettersson E, Lichtenstein $P$, Larsson $H$, Song $J$, Agrawal AD, Børglum CM, et al. Genetic influences on eight psychiatric disorders based on family data of 4408646 full and halfsiblings, and genetic data of 333748 cases and controls. Psychol Med. 2019;49(7):1166-73.

https://doi.org/10.1017/S0033291718002039

[40]. Chen MH, Pan TL, Huang KL, Hsu JW, Bai YM, Su TP, et al. Coaggregation of major psychiatric disorders in first-degree relatives of individuals with attention-deficit/hyperactivity disorder: A nationwide population-based study. J Clin Psychiatry. 2019;80(3):18m12371.

https://doi.org/10.4088/JCP.18m12371

[41]. Lopez JP, Brivio E, Santambrogio A, De Donno C, Kos A, Peters M, et al. Single-cell molecular profiling of all three components of the HPA axis reveals adrenal ABCB1 as a regulator of stress adaptation. Sci Adv. $2021 ; 7(5)$ :eabe4497.

https://doi.org/10.1126/sciadv.abe4497

[42]. Qian W, Yu C, Wang S, Niu A, Shi G, Cheng $\mathrm{Y}$. Depressive-like behaviors induced by chronic social defeat stress are associated with HDAC7 reduction in the nucleus accumbens. Front Psychiatry. 2021;11:586904.

https://doi.org/10.3389/fpsyt.2020.586904

[43]. Dhama K, Latheef SK, Dadar M, Samad HA, Munjal A, Khandia R, et al. Biomarkers in stress related diseases/disorders: Diagnostic, prognostic, and therapeutic values. Front Mol Biosci. 2019;6:91. https://doi.org/10.3389/fmolb.2019.00091

[44]. Le-Niculescu H, Roseberry K, Levey DF, Rogers J, Kosary K, Prabha S, et al. Towards precision medicine for stress disorders: Diagnostic biomarkers and targeted drugs. Mol Psychiatry. 2020;25(5):918-38. https://doi.org/10.1038/s41380-019-0370-z

[45]. Le-Niculescu H, Roseberry K, Gill SS, Levey DF, Phalen PL, Mullen J, et al. Precision medicine for mood disorders: Objective 
assessment, risk prediction, pharmacogenomics, and repurposed drugs. Mol Psychiatry. 2021;26(7):2776-804. https://doi.org/10.1038/s41380-021-01061-w

[46]. Dantzer R, Cohen S, Russo SJ, Dinan TG. Resilience and immunity. Brain Behav Immun. 2018;74:28-42. https://doi.org/10.1016/j.bbi.2018.08.010

[47]. Bouillon-Minois JB, Trousselard M, Thivel D, Gordon BA, Schmidt J, Moustafa F, et al. Ghrelin as a biomarker of stress: A systematic review and meta-analysis. Nutrients. 2021;13(3):784. https://doi.org/10.3390/nu13030784

[48]. Kim P. How stress can influence brain adaptations to motherhood. Front Neuroendocrinol. 2021;60:100875. https://doi.org/10.1016/j.yfrne.2020.100875

[49]. Aschbacher K, Hagan M, Steine IM, Rivera L, Cole S, Baccarella A, et al. Adversity in early life and pregnancy are immunologically distinct from total life adversity: Macrophageassociated phenotypes in women exposed to interpersonal violence. Transl Psychiatry. 2021;11(1):391. https://doi.org/10.1038/s41398-021-01498-1

[50]. Heim CM, Entringer S, Buss C. Translating basic research knowledge on the biological embedding of early-life stress into novel approaches for the developmental programming of lifelong health. Psychoneuroendocrinology. 2019;105:12337.

https://doi.org/10.1016/j.psyneuen.2018.12.01 1

[51]. Hanson JL, Williams AV, Bangasser DA, Catherine J. Peña CJ. Impact of early life stress on reward circuit function and regulation. Front Psychiatry. 2021. https://doi.org/10.3389/fpsyt.2021.744690

[52]. Serpeloni F, Nätt D, Assis SG, Wieling E, Elbert T. Experiencing community and domestic violence is associated with epigenetic changes in DNA methylation of BDNF and CLPX in adolescents. Psychophysiology. 2020;57(1):e13382. https://doi.org/10.1111/psyp.13382

[53]. Scheinost D, Spann MN, McDonough L, Peterson BS, Monk C. Associations between different dimensions of prenatal distress, neonatal hippocampal connectivity, and infant memory. Neuropsychopharmacology. 2020;45(8):1272-9. https://doi.org/10.1038/s41386-020-0677-0

[54]. Giacobbo LB, Doorduin J, Klein HC, Dierckx RAJO, Bromberg E, de Vries EFJ. Brain- derived neurotrophic factor in brain disorders: Focus on neuroinflammation. Mol Neurobiol. 2019;56(5):3295-312. https://doi.org/10.1007/s12035-018-1283-6

[55]. Miao Z, Wang Y, Sun Z. The relationships between stress, mental disorders, and epigenetic regulation of BDNF. Int J Mol Sci. 2020;21(4):1375. https://doi.org/10.3390/ijms21041375 